\title{
LA MUJER EN LA PROPAGANDA POLÍTICA REPUBLICANA DE LA GUERRA CIVIL ESPAÑOLA
}

\section{WOMEN'S IMAGE AS USED IN THE CONTEXT OF REPUBLICAN POLITICAL PROPAGANDA DURING THE SPANISH CIVIL WAR}

María Gómez Escarda Instituto Universitario General Gutiérrez Mellado-UNED, Madrid. España/Spain mgomez@bec.uned.es

Recibido/Received: 09/04/08

Aceptado/Accepted: 06/08/08

\section{RESUMEN}

Durante la Guerra Civil la propaganda política republicana recurrió en numerosas ocasiones a la imagen de la mujer. En este trabajo se analizan los carteles dirigidos a la mujer o que utilizan imágenes femeninas y la propaganda de la Asociación de Mujeres Antifascistas. Se recurre a una imagen masculinizada cuando se refieren a las milicianas o al trabajo de la mujer en las fábricas o en el campo, mientras que esta imagen se suaviza y se dramatiza en aquéllos referidos a bombardeos, a peticiones de auxilio y -en algunos casos- al papel de la mujer en la retaguardia.

PALABRAS CLAVE

Propaganda política, mujer, igualdad, milicianas, retaguardia.

\begin{abstract}
During the civil war the republican political propaganda used the image of woman many times. This paper analyses the posters addressed to women, the posters which used women's images and the propaganda of the Antifascist Women Association. This propaganda used to depict women as men or in a very man like fashion, when talking on militia women or about the work of women in the agricultural sector. However the propaganda used to be much more extreme, either being softer or sometimes by being more dramatic about women when talking on bombings, help petitions and the role of women in the battlefield.
\end{abstract}

\section{KEYWORDS}

Political propaganda, woman, equality, militia women, rearguard.

\section{INTRODUCCIÓN}

En épocas de crisis se acentúa la necesidad de llamar la atención con todo tipo de instrumentos de propaganda y no me refiero únicamente a la propaganda política que en campañas electorales, en tiempos de guerra..., multiplica su 
producción y conlleva una explosión de ideas y formas de expresión que normalmente no se produce en un contexto de 'calma' social y política; también en momentos de crisis económica o de caída de las ventas las empresas multiplican sus campañas para llamar la atención de sus clientes.

En cuanto a la propaganda política es un arma muy importante, por ejemplo a la hora de atraer y convencer a las personas que no tienen muy clara su intención de voto en época de elecciones, pero también es una manera de dar a conocer e informar sobre ciertas cuestiones que podrían permanecer ocultas o lejanas para una parte de la sociedad, que o bien no tiene un fácil acceso a la información, o no se interesan por los acontecimientos hasta que se les llama la atención de alguna forma. Así para una gran parte de la sociedad durante la Guerra Civil Española la propaganda sirvió en parte para que el pueblo estuviera informado, como sucedió en el caso de los carteles, panfletos, tarjetas postales y la información emitida por radio respecto al asedio sufrido por Madrid y que llamaba a las familias -sobre todo a mujeres con sus hijos- a evacuarse y a los hombres a que se alistaran al ejército republicano para defender la ciudad contra los invasores.

La producción de carteles durante la República, la Guerra Civil y la posguerra fue en su mayoría del bando republicano. Muchos de los autores provenían del ámbito comercial y copiaron las técnicas que utilizaban en el mismo. En lo que respecta al bando nacional, utilizaron principalmente la radio para emitir sus discursos políticos, aunque también se realizaron carteles propagandísticos durante la guerra y posteriormente durante la dictadura franquista. Los carteles, panfletos, octavillas..., sirven de información no sólo para dar a conocer las diferentes ideologías políticas del momento, también ayudan a conocer la situación, en este caso de las mujeres en la sociedad española de aquella época, sus reivindicaciones y las desigualdades a las que debían enfrentarse.

Los discursos respecto a la mujer eran muy diferentes dependiendo de la corriente ideológica de la que surgieran. Por un lado estarían los realizados por Pilar Primo de Rivera y su Sección Femenina, que relegaban en su propaganda a la mujer al ámbito doméstico, eso sí según su discurso el Servicio Social permitía a muchas mujeres salir de su círculo y conocer y realizar actividades diferentes, como la educación física. Por otro lado habría que fijarse en las voces de las feministas de la época que en su mayoría luchaban por la libertad y reivindicaban derechos básicos para la mujer, aunque aquí habría también que diferenciar entre distintos tipos de discursos, desde los incendiarios de las anarquistas hasta los más moderados de algunas socialistas y comunistas.

Este trabajo no pretende ser un alegato sobre las desigualdades y las injusticias que se han producido y se siguen produciendo en contra de las mujeres, pero sí que me gustaría esclarecer algunos puntos sobre el papel que desempeñaron muchas mujeres en la Guerra Civil Española, porque, no sólo desde las filas fascistas sino también desde muchos sectores republicanos, se intentó dejar a la mujer en un segundo plano, se ridiculizó su papel dentro del ejército y se utilizaron 
sus capacidades y su fuerza de trabajo en la retaguardia mientras duró la guerra en unas condiciones laborales y salariales precarias.

Como explica muy bien Antonina Rodrigo (1999:23)... "ellas también hicieron la guerra, estuvieron en el maquis, en la resistencia, y además, permanecían sometidas, a las vicisitudes de la casa, de la familia, del trabajo. La que militaba asumía su compromiso político, sin cortar las riendas del hogar, donde reinaba la penuria".

El análisis de la situación de la mujer en la época de la Guerra Civil española se va a basar principalmente en dos aspectos: por un lado los carteles republicanos de guerra dirigidos a la mujer o que utilizan una imagen femenina $\mathrm{y}$, por otro, la propaganda política de la Asociación de Mujeres Antifascistas -AMAque se fundó en 1934 y que estaba integrada por comunistas, socialistas, republicanas, republicanas católicas vascas y mujeres no politizadas.

\section{LA MUJER EN LOS CARTELES DE LA GUERRA CIVIL ESPAÑOLA}

Los carteles en España tienen sus orígenes en los anuncios de corridas de toros y de fiestas patronales y fueron realizados en un primer momento en los talleres de Barcelona y Valencia. Con posterioridad serán las fábricas, los comercios..., los que utilizarán este método para dar a conocer sus productos.

El proceso que se seguía hasta llegar al cartel como tal lo resume Mike Blacksmith exponiendo que "el cartelista pintaba, dibujaba o componía su cartel en el estudio, una vez acabado lo llevaba al taller, y un dibujante litógrafo lo copiaba a las planchas, comenzando entonces la verdadera impresión". Josep Renau (1976:66) explica que el cartelista, al realizar su trabajo, está influenciado por la visión, la ideología y la propia situación personal que vive "como artista y como hombre". Así, al principio del conflicto las fórmulas publicitarias se adaptaron rápidamente a los motivos de la revolución y la guerra, pero después de ocho meses los carteles pierden su calidad y su dramatismo, probablemente porque los propios artistas estarían sufriendo los avatares y las carencias de la guerra.

\section{CARACTERÍSTICAS Y FUNCIONES DE LOS CARTELES DE GUERRA}

En palabras de Inmaculada Julián (1993:118) las herramientas perfectas para conseguir una propaganda política eficaz en tiempos de guerra son el cartel, la prensa diaria y la radio. En los carteles debe mezclarse la imagen y la consigna porque su función principal, según la autora, es la de transmitir en la retaguardia lo que ocurre en el frente para orientar sobre la manera de actuar de la población civil. El problema al que se enfrentaban es que la prensa diaria no llegaba a todos los lugares y además los carteles se utilizaron mayoritariamente en las grandes ciudades como Madrid, Barcelona y Valencia, por ello la radio -cartel 1- se convirtió en un arma informativa muy importante pues llegaba a aquellos lugares a los que no se 
tenía fácil acceso. Otra de las formas de difundir información durante la guerra civil fueron las canciones, los poemas y leyendas que hablaban de los héroes y heroínas del frente, de las batallas y los bombardeos, de los refugiados...

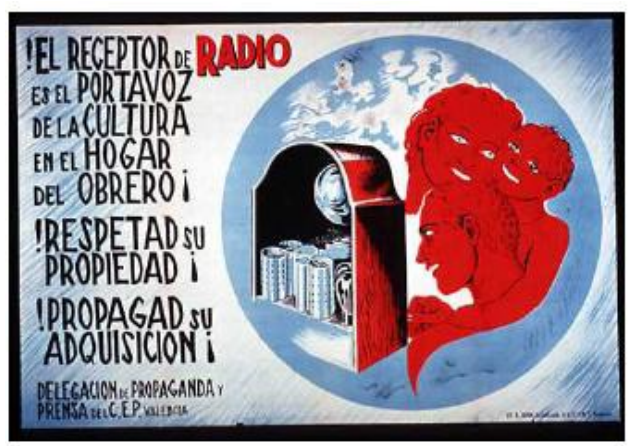

Cartel 1: Desconocido, Valencia 1937

El cartelismo español vivió una explosión de creatividad en los primeros años de la Guerra. En un principio fueron los autores de los carteles comerciales los que cogieron la batuta y se dedicaron a enviar mensajes propagandísticos en contra del fascismo y en favor de la defensa del gobierno republicano elegido por el pueblo.

Algunos autores indican que la producción de carteles republicanos referidos a las mujeres tiene dos vertientes distintas, por un lado estarían los carteles de las organizaciones oficiales, sindicales y de los propios partidos políticos realizados por sus secciones de propaganda y cuya función principal consistió en concienciar políticamente a las mujeres; para ello se combinaba la imagen de la mujer trabajadora con la de mujer revolucionaria. Por otro lado, estarían los carteles realizados por Mujeres Libres que era la única organización feminista española existente en 1936; en ellos se aúnan imágenes que ratifican el puesto de la mujer en la retaguardia y consignas de revolución social portadoras de los objetivos del feminismo proletario.

\section{VISIÓN SOCIAL DE LA MUJER A TRAVÉS DE LOS CARTELES}

La situación de la mujer en los años de la guerra se pone de manifiesto en los numerosos carteles de la época; desde los que representan la imagen revolucionaria de las milicianas a los que reflejan el dolor de una madre que huye de los bombardeos, los carteles nos dan una visión muy detallada del papel que 'jugaban' las mujeres.

La mujer obtiene el derecho al voto en 1931 y por ello los partidos políticos comienzan a dirigir sus campañas al nuevo electorado femenino. Sin embargo se alzaron voces en contra porque se creía que la mujer no tenía capacidad intelectual 
para entender los temas de la política. En el cartel 2 en el que se mezclan tres elementos propagandísticos: por un lado, la mujer ejerciendo su derecho al voto; por otro lado, la propaganda electoral del Frente Popular y por último se pide la amnistía para los presos encarcelados en la represión de octubre de 1934.

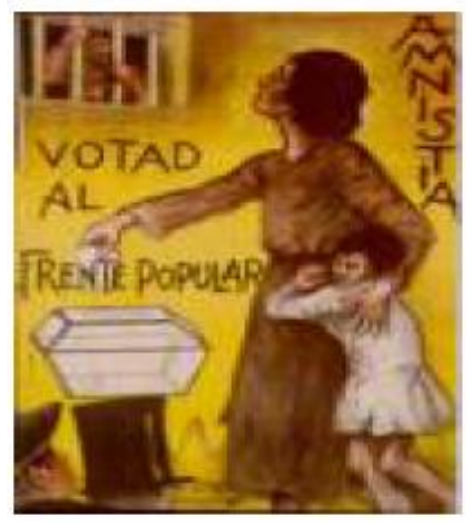

Cartel 2: Desconocido, 1934

Aunque en esta época revolucionaria las mujeres comienzan a salir un poco de su reducido círculo y se empieza a utilizar una imagen rupturista en los carteles republicanos, en el fondo, siguen soportando la sumisión al sistema patriarcal y tradicionalista. Este nuevo modelo no representa a una nueva mujer emergente de un nuevo contexto sociopolítico sino que más bien se crea una imagen artificial de la mujer para cubrir las necesidades que van surgiendo, tanto en tiempo de elecciones como en tiempo de guerra.

\subsection{Las Milicianas}

El caso de las mujeres milicianas es un claro ejemplo de cómo la propaganda puede transformar en poco tiempo los discursos y las opiniones. Según afirman Carmen Alcalde y Lidia Falcón (1976:123) las anarquistas fueron las primeras mujeres que se incorporaron activamente a la lucha como milicianas; además en el periódico Frente Libertario se llevó a cabo una importante campaña de enrolamiento de la mujer en la guerra lanzando consignas y empapelando las calles con los carteles de propaganda. Pero es preciso aclarar que las motivaciones para ir a los frentes de lucha no eran únicamente políticas pues una parte muy importante de ellas tenían otras razones como la de acompañar a sus familiares, hijos y amigos e incluso para vengar alguna muerte cercana. Lucharon en el frente de Segovia donde se creó un batallón de mujeres; pero también en Cataluña desde donde enviaron un batallón femenino para defender Mallorca; en Asturias se formó 
un pequeño grupo de milicianas y una de ellas llegó a ser Capitán de una Compañía de ametralladoras.

Durante los primeros meses de conflicto fueron un símbolo de la lucha contra el fascismo. Se las representaba con una imagen moderna, eran jóvenes vestidas con su mono azul -uniforme de trabajo proletario-, y cargando con un fusil. Lo que se pretendía conseguir era la ruptura frente al orden establecido, en el que la mujer estaba subordinada al poder patriarcal y conseguir el derecho a la igualdad de condición. Teófila Madroñal (Rodrigo, 1999:64) reivindicaba el papel combativo que llevaron a cabo sus compañeras milicianas, porque no sólo lucharon en los frentes sino que además se encargaron de arengar a los varones para que salieran a la calle y se alistaran en el ejército.

En lo que respecta a las milicianas cabe señalar que según numerosas fuentes la división de tareas se repetía también en el frente, viéndose la mujer relegada a realizar tareas 'propias' de su sexo como lavar la ropa, cocinar y realizar las funciones sanitarias. En contra de esta idea se expone el testimonio de una miliciana llamada Fifí (Alcalde y Falcón, 1976:171) que afirmaba que nunca pasó

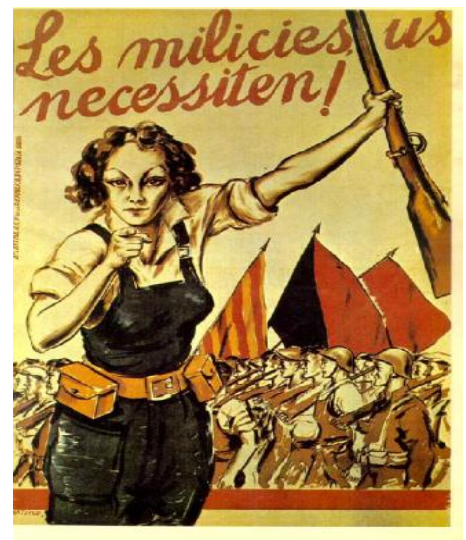

Cartel 3: Arteche, Barcelona 1936

miedo en el frente y que jamás temió el asalto de ningún compañero; explica también que era ella la que hacía la comida pero no por el hecho de ser mujer, sino porque los hombres eran mucho más lentos y no podían permitirse el lujo de perder el tiempo y de pasar hambre. Aunque Antonia García (Nash, 1999:173) comunista y activista antifascista afirmaba que era frecuente el acoso sexual y confirmaba el hecho de que "los hombres son comunistas, socialistas o anarquistas de cintura para arriba".

Durante unos meses las mujeres milicianas vivieron una situación peculiar, por un lado eran admiradas por su entrega y su arrojo, como en el caso de Lina 
Odena, Casilda Méndez, Rosario Sánchez Mora alias 'La Dinamitera' -que perdió una mano al explosionarle una bomba; por otro lado tuvieron que enfrentarse a las críticas y el desprecio, ya que, se comentaba que las mujeres iban al frente para mantener relaciones con los soldados -contagiándoles enfermedades- y para buscar marido. Además desde la propaganda del bando nacional se difundió la idea de que muchas milicianas eran prostitutas que buscaban hacer negocio con los soldados y como afirma Teófila Madroñal, aunque bien es cierto que algunas profesionales fueron al frente no eran ellas las que provocaban enfermedades venéreas.

En este sentido resulta curioso el "mensaje eugénico a las mujeres" difundido por el Doctor anarquista Félix Martí (Nash, 1999:171) en el que se afirmaba que la retirada de las mujeres de los frentes podría ayudar a reservar la energía para el esfuerzo bélico; así el deber de las mujeres sería facilitar la continencia, la disciplina sexual y la armonía en las relaciones eróticas. Parece que no eran sólo los discursos fascistas los que veían a la mujer como una especie de 'demonio' al acecho de los 'pobres soldados'. Esta preocupación fue el objetivo de una importante campaña de concienciación, y son numerosos los carteles que tratan sobre el tema de las enfermedades venéreas. Como en el cartel 4 en el que se ve un combatiente con la cabeza caída y una mujer muy pálida, en actitud cariñosa y cuya mano esquelética rodea la cintura del soldado, representando la enfermedad y la muerte.

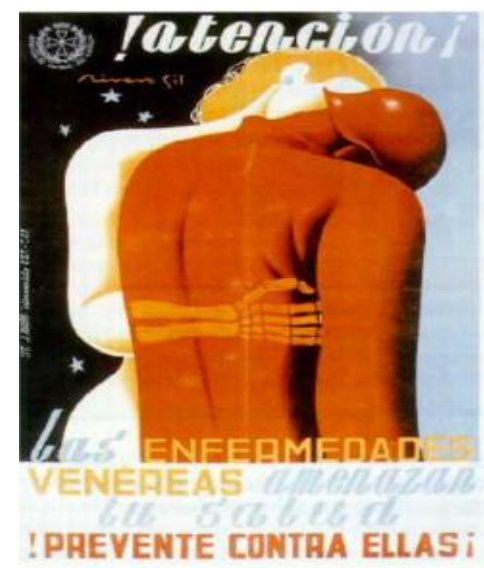

Cartel 4: Rivero Gil, Valencia 1937

En octubre de 1936 Largo Caballero estableció una serie de disposiciones para retirar a las mujeres del frente y trasladarlas a la retaguardia, se argumentaba como excusa el que no era un lugar para una mujer y que no estaban preparadas para formar parte de un ejército estructurado. En un instante, las milicianas pasaron de ser glorificadas a ser ridiculizadas. Pero hay que dejar muy claro que no sólo los fascistas habían criticado a estas mujeres porque no cumplían con el rol que tenían asignado también algunos sindicatos, partidos e incluso organizaciones femeninas 
plantearon la necesidad de trasladar a las mujeres a la retaguardia. Así en 1937 los comunistas consiguen crear un ejército regular eliminando a las milicias y $\sin$ contemplar la presencia de las mujeres en el mismo.

\subsection{La retaguardia: El trabajo de las mujeres en el campo y en la ciudad}

M. Andiano afirmaba en 1936 que "en los primeros días de sublevación, las mujeres supieron comprender que en aquel momento lo urgente era acrecentar el entusiasmo de los que se lanzaban a la lucha, y se unieron a ellos empuñando a su vez las armas, con tanto o más coraje que los hombres (...) Los campos de batalla se tiñeron con la sangre de las valerosas mujeres, que enroladas en las milicias, opusieron su empuje al avance enemigo (....) Las mujeres han cumplido con su deber (....) Pero ahora el deber primordial es reintegrarse en la retaguardia, dedicarse al trabajo en las industrias, comercios, oficinas. La marcha de la nación no debe ser interrumpida porque falten los brazos masculinos, que impulsaban el engranaje de su economía. Estos brazos han de ser suplidos por la mujer (...) A la retaguardia, todas las mujeres al trabajo, ese es vuestro puesto. A seguirlo, y ¡salud!” (Alcalde y Falcón, 1976:125)

La retaguardia es un elemento clave en todo conflicto armado ya que es en ella donde se lleva a cabo la actividad económica y productiva que asegura el abrigo, el alimento, la asistencia sanitaria, la producción armamentística... que se necesita en el frente; la propaganda representa, de nuevo, un importante instrumento de información y concienciación. La propaganda política en este ámbito ofrece una serie de contradicciones respecto al papel de la mujer muy interesantes pues si bien se multiplican los carteles y discursos que apelan a la importancia del trabajo femenino en la retaguardia, no son menos los discursos que pretenden tranquilizar a los hombres en el sentido de que los puestos de trabajo ocupados por las mujeres serán devueltos a las manos masculinas cuando acabe el conflicto armado. En todas las sociedades de guerra se utiliza la mano de obra femenina para cubrir las bajas producidas por el alistamiento de los varones en el ejército. El lema "Los hombres al frente, las mujeres a la retaguardia" será la consigna utilizada por la mayoría de los partidos políticos y de las asociaciones de mujeres. Con el aumento de los puestos ocupados por mujeres comienzan a surgir reivindicaciones como la equiparación salarial con los varones, el reconocimiento de la capacidad profesional de las mujeres, el derecho a una capacitación técnica-profesional y la necesidad de crear redes asistenciales que aliviaran a la mujer del trabajo en el hogar. 


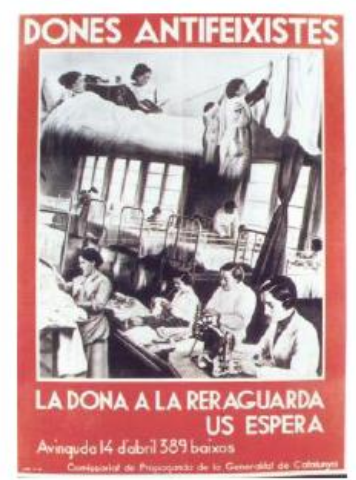

Cartel 5: Desconocido, Cataluña 1936

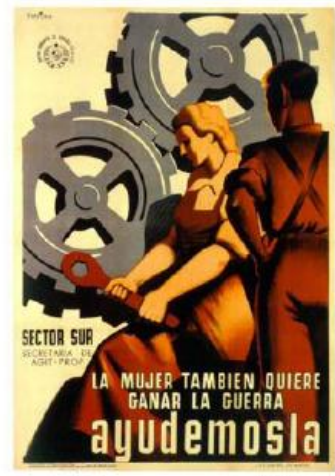

Cartel 6: Parrilla, Madrid 1937

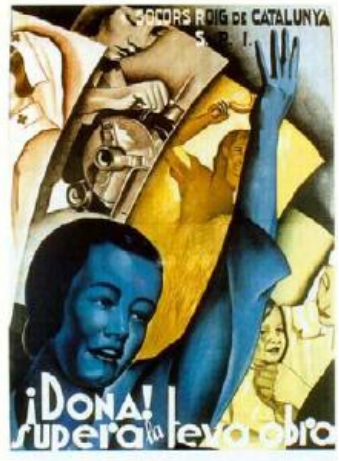

Cartel 7: Desconocido, Cataluña 1938

Resultan curiosos los mensajes utilizados en los carteles orientados al trabajo de la mujer en la retaguardia ya que en el cartel 5 la retaguardia está representada por aquellas labores consideradas como 'típicamente femeninas' y que las mujeres realizaban fuera y dentro de sus hogares. En el cartel 6 se representa a una trabajadora que es capaz de mover sola los engranajes de la maquinaria aunque, eso sí, bajo la supervisión de un varón. En el cartel 7 el Socorro Rojo de Cataluña anima a la mujer a superar su obra y la representa en diferentes labores, además en este caso introduce la imagen de una mujer con una hoz, como símbolo de su trabajo en el campo.

Las actividades que se realizaban en la retaguardia eran de carácter muy diverso aunque es necesario diferenciar entre las labores que se desarrollaban en los ámbitos urbanos y en los rurales. En las ciudades las mujeres se hicieron cargo de guarderías y centros asistenciales para los hijos de los combatientes y de las trabajadoras; se crearon también hospitales de sangre donde las mujeres ejercían labores sanitarias y acompañaban a los enfermos; se dedicaron a la confección de ropa -sobre todo en las campañas de invierno; se ocuparon en la industria armamentística; hubo conductoras de tranvías, carteras y encargadas del abastecimiento de las tropas; se pusieron de moda las denominadas 'madrinas de guerra' que mantenían correspondencia con los soldados que se encontraban en el frente; éste papel que fue creado por las mujeres de Izquierda Republicana y por las propias comunistas fue muy criticado por Mujeres Libres pues lo veían como un símbolo tradicional y burgués. Aunque en un principio estas tareas no eran remuneradas en marzo de 1937 se promulgó un decreto por el que se establecía un salario por dichas actividades.

En cuanto al trabajo de la mujer en el ámbito rural la verdad es que la situación no cambió mucho durante el período de guerra, ya que las mujeres rurales trabajaban en la agricultura y la ganadería antes de que empezara el conflicto, además de ocuparse de las labores familiares y domésticas; una de las pocas cosas que sí pueden parecer sorprendentes es el hecho de que aparecieran imágenes de 
mujeres conduciendo tractores. Se crearon Brigadas de Choque (Nash, 1981:259) que, normalmente los fines de semana, se encargaban de ayudar en el trabajo del campo, impulsar la creación de granjas e intentaban además elevar el nivel cultural de las campesinas impartiendo clases de cultura general.

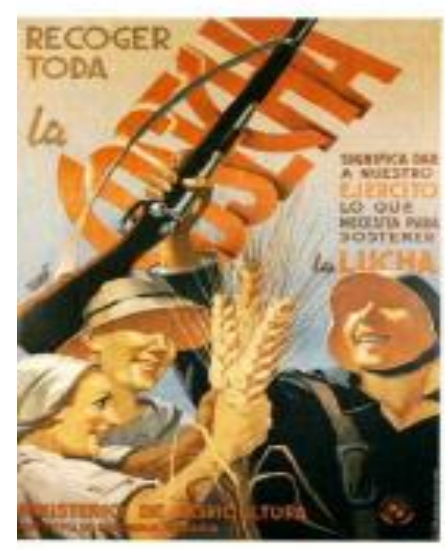

Cartel 8: Canet, Valencia

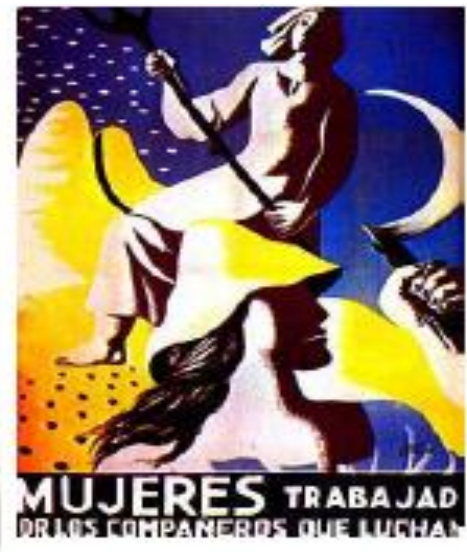

Cartel 9: Autonio, Madrid

En estos dos carteles se utilizan tres símbolos que, como afirma Gary Yankers (Julián, 1993:61) son utilizados normalmente por los sectores de izquierda, como son la hoz, símbolo de la unión de los campesinos; las espigas de trigo, en representación de la fertilidad de la tierra y el futuro alentador que espera una vez conseguida la victoria de la revolución; y en tercer lugar el fusil tendido por encima del brazo del soldado que simboliza la revuelta armada en contra del opresor.

Aunque la labor productiva de las mujeres, tanto en las industrias como en los campos, en uno de los temas más recurrentes de los carteles de la época, no hay que olvidar que también son muchos los carteles referidos a la labor sanitaria y educativa llevada a cabo por las mujeres en los frentes y en la retaguardia. En los hospitales de sangre y en los hogares habilitados para los niños refugiados aparece la imagen maternal de la mujer que cuida al soldado herido y al niño huérfano, como si fueran sus propios hijos.

El problema que se plantea respecto al trabajo de la mujer en la retaguardia es que, como muy bien expresan Carmen Alcalde y Lidia Falcón (Alcalde y Falcón, 1976:99) “...tras todas las guerras, las mujeres, después de haber sido útiles en la sustitución del hombre en el trabajo, han devuelto el puesto al marido, al hermano, al padre y han regresado, mitad víctimas y mitad cómplices, a ese tradicional y castrador papel de reinas del hogar". 


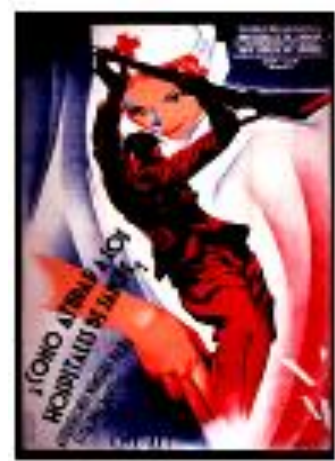

Cratol 10: Dovcozocido

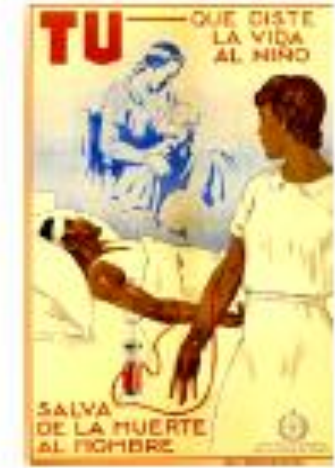

Cartal 11: Ponzzor, Valeceis 1937

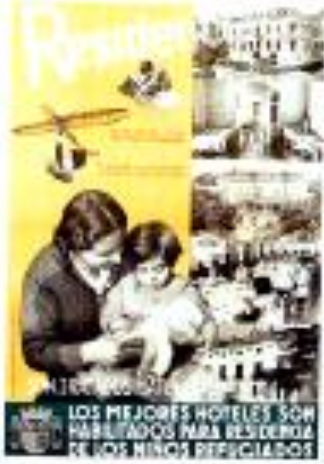

Caral 12: Haary, Buceloen 1938

\subsection{Los bombardeos y la huida de la población civil}

Los carteles y fotomontajes que hacen referencia a los bombardeos o a la necesidad de evacuar alguna ciudad, se representan normalmente con la imagen de una mujer con el gesto desgarrado por el dolor y con un niño en brazos o cogido de la mano. No es de extrañar que se elija a la mujer como objeto para realizar este tipo de campañas pues ellas son supuestamente el 'sexo débil' y conmueve más ver a una mujer en una situación semejante. Sin embargo también habría que señalar que en las ciudades el número de mujeres superaba al de hombres, ya que, muchos estaban en el frente o habían muerto en combate y era a ellas a las que había que lanzar una campaña propagandística para que abandonaran las ciudades, con lo que se conseguiría además de alejarlas del peligro de los bombardeos que los combatientes pudieran aprovechar los escasos recursos que quedaban.

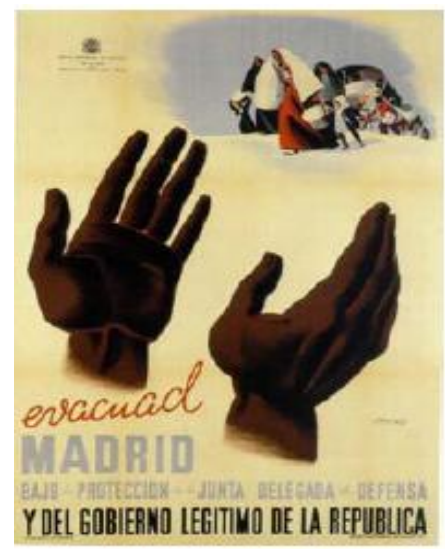

Cartel 13: Briones, Madrid 1937 
En el ejemplo, podemos ver a un grupo de mujeres con sus niños de la mano, caminando por la nieve, con los pocos bienes que pudieron recoger antes de huir de sus casas. Pero, aparecen las manos masculinas enormes, que representan el cobijo y la protección de la Junta Delegada de la Defensa y del Gobierno legítimo de la República.

Hay que señalar que además del castellano y el catalán se realizaron carteles en otros idiomas. Esta circunstancia se explica por la necesidad de informar al resto del mundo de la situación que se estaba viviendo en España en aquellos momentos; además los y las brigadistas internacionales -como Gerda Taro que luchó en el Frente Catalán, o Marion Merriman que pertenecía a la Brigada Lincoln-, fueron un elemento clave pues gracias a ellos se hizo patente la necesidad de unirse en la lucha contra un fascismo que no tardaría en lanzar sus redes por el resto de Europa.

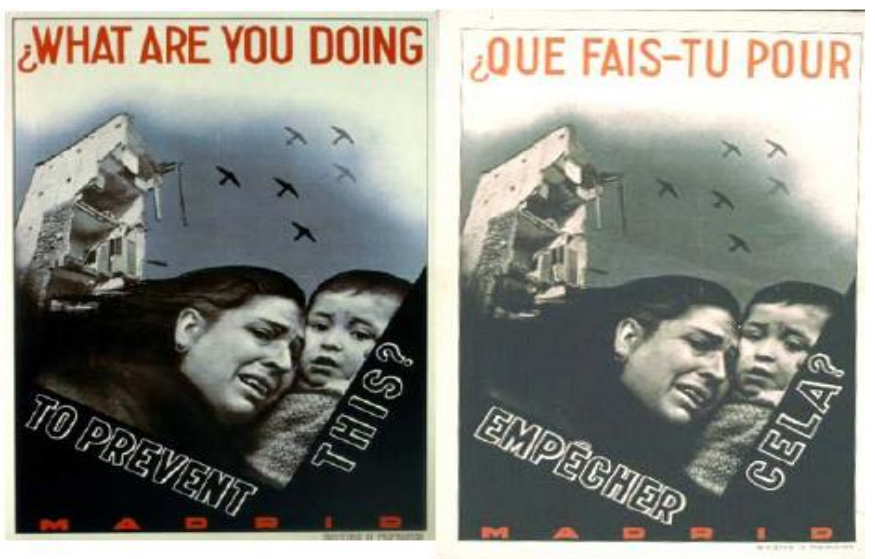

Cartel 14: Desconocido, Madrid 1937

El Ministerio de Propaganda realizó este cartel en tres idiomas -castellano, inglés francés. Con su eslogan “¿Qué estás haciendo para prevenir esto?”, los tonos grises y la composición de las imágenes pretendía remover las conciencias de los espectadores y fomentar el alistamiento en las filas republicanas de los extranjeros. Sin embargo el Comité de No Intervención firmado por Francia e Inglaterra en agosto de 1936 y ratificado por otros 27 países frenó el apoyo al gobierno republicano; sólo recibió la ayuda de la Unión Soviética y Méjico. Además del apoyo de las Brigadas Internacionales, el Socorro Rojo Internacional que tenía su sede en París y que canalizaba la ayuda de sindicatos, organizaciones obreras y partidos políticos de la izquierda internacional representó para la República Española un ejemplo de solidaridad de la clase trabajadora de todo el mundo en su lucha contra el fascismo. 


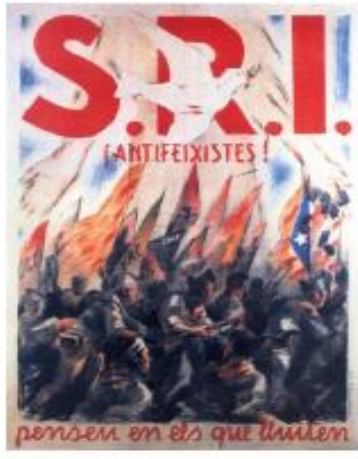

Cartel 15: Desconocido

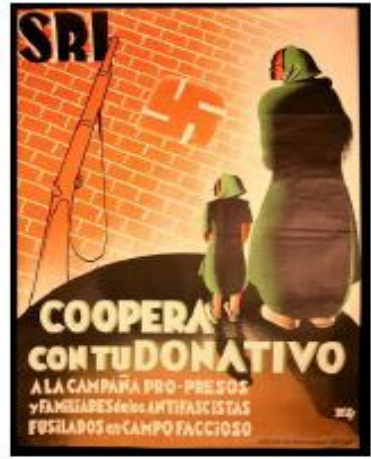

Cartel 16: Desconocido

En otros carteles, como en el que se muestra a continuación, se pretende alentar a los trabajadores de la retaguardia y al gobierno para que construyan más refugios que eviten que se produzcan situaciones como la que se representa. Una chica joven, vestida con un atuendo blanco -símbolo de pureza- manchado de sangre, cae muerta en el suelo frío y gris, por el ataque de las armas fascistas. El poder de las bombas grises -'adornadas' con símbolos fascistas-, contrasta con la delicadeza y la palidez de la muchacha que yace muerta.

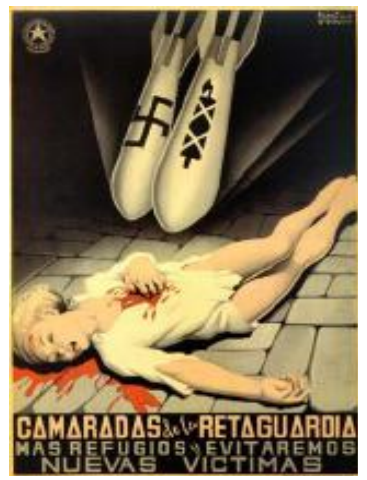

Cartel 17: Parilla, Valencia 1938

\section{LA MUJER EN LA PROPAGANDA POLÍTICA DE LA ASOCIACIÓN DE MUJERES ANTIFASCISTAS -AMA-}

La Asociación de Mujeres Antifascistas -AMA- se fundó en 1934, y estaba formada por comunistas, socialistas, republicanas, republicanas católicas vascas, y por mujeres no 'politizadas'. Aunque representaba un carácter multipartidista fue criticada sobre todo por las anarquistas, ya que, el Partido Comunista ejercía una influencia enorme sobre la asociación porque tanto la dirección, como sus programas y políticas tenían una clara orientación comunista. En 1938 el Comité Ejecutivo reconoció que la propaganda de la AMA había descuidado a las mujeres 
que no estaban afiliadas como las amas de casa, las trabajadoras asalariadas y las intelectuales. Por lo que se empezaron a lanzar mensajes para 'captar' a mujeres pertenecientes a estos colectivos.

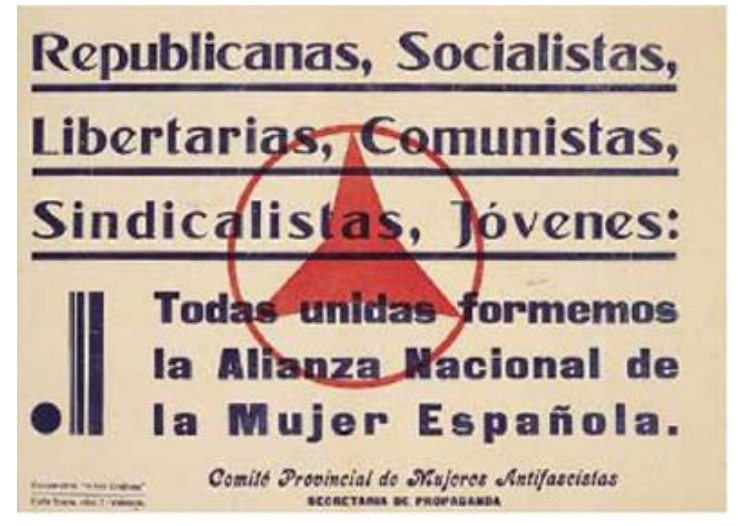

Cartel 18: Desconocido, Valencia

Emilia Elías (Nash, 1976:224), ocupó el cargo de Secretaria General del Comité Nacional de la AMA y concretaba en su programa político los siguientes puntos:

- Primero.-Lucha contra el fascismo y realización de una alianza nacional de mujeres.

- Segundo.-Lucha por la paz.

- Tercero.- Lucha por la defensa de la cultura de la mujer y derecho de todos los niños a tener una educación adecuada.

- Cuarto.-Derecho a la libertad, a manifestarse libremente y a su autodeterminación.

- Quinto.-Justicia igual para todos.

- Sexto.-Incorporación de la mujer a la vida política y social, y liberación de la mujer de una maternidad agobiadora.

Aunque en este programa se establecieron muchos puntos en favor de la igualdad de las mujeres la AMA sostenía que la Guerra Civil no era el momento más indicado para impulsar un verdadero cambio revolucionario respecto a la situación de la mujer en la sociedad de la época y basaron sus actuaciones en la lucha contra el fascismo y la defensa del gobierno legítimo. Así el fascismo se retrató como un enemigo para la familia, como un símbolo de la esclavitud y la humillación para la mujer. Sólo un pequeño grupo se dedicó a la lucha contra los problemas y las desigualdades de las mujeres, no obstante se centraron en el terreno laboral, en temas como la discriminación salarial y el permiso por maternidad. 
Durante la guerra las mujeres comenzaron a ocupar puestos que habían estado reservados a los hombres y éstos veían a sus compañeras como una amenaza para su trabajo en el futuro; tuvieron que intervenir los sindicatos y partidos políticos pero para tranquilizar a los varones asegurándoles que se trataba de una situación transitoria debido a la necesidad de mano de obra en la retaguardia no para defender un cambio revolucionario de la situación de la mujer.

Dolores Ibárruri -Pasionaria-, presidenta de la AMA, representaba un símbolo de la tragedia de las madres en la Guerra Civil y abogaba por la necesidad que tenían las mujeres de cierta autonomía e independencia como base para su emancipación, incluso llegó a señalar que no tenían que vivir en función de su marido y de sus hijos. Sin embargo también dedicó sus esfuerzos a tranquilizar a los trabajadores varones que se sentían temerosos porque la mujer estaba 'usurpando' sus puestos de trabajo, explicándoles que sólo se trataba de una situación transitoria y que cuando terminara la guerra las mujeres les devolverían sus trabajos.

Con el estallido de la guerra, Pasionaria realizó una importante campaña de propaganda política que aumentó su fama en la España republicana; Nieves Torres (Mangini, 1997:87) estaba en el taller de costura donde trabajaba Pasionaria en 1936 y explica que "el 7 de noviembre, todos pensábamos que era el fin de Madrid. Lo único que podíamos pensar era que los fascistas iban a entrar en la ciudad (...) Entonces Dolores gritó: ¡No pasarán! Lo dijo a los soldados, a la retaguardia, a todos, y todos se levantaron y dijeron No, no, no pasarán, itenemos que defender Madrid con uñas y dientes!" En París, en 1936, adoptó otro de sus eslóganes más célebres de la guerra, "Más vale morir de pie que vivir de rodillas". Pasionaria fue nombrada Comandante Honoraria del Quinto Regimiento y en su discurso de agradecimiento arengaba a las tropas -a los hombres- con las siguientes palabras: "Si (los fascistas) triunfan y (os envían) a los campos de concentración, podéis imaginar lo que os dirán vuestras esposas y madres: Llorad como mujeres, pues no supisteis luchar como hombres" (Nash, 1976:137)

En la Conferencia de Mujeres Antifascistas, celebrada en Valencia en octubre de 1937, se pusieron de manifiesto una serie de reivindicaciones para mejorar la condición femenina en general; se buscaba la integración de la mujer en la fuerza laboral, la igualdad salarial, la creación de una estructura de cantinas, guarderías e instalaciones colectivas para el cuidado de los niños. Aunque todas estas medidas buscaban más el conseguir un verdadero compromiso antifascista con el trabajo de las mujeres en la retaguardia que reivindicar un cambio en su situación. La principal fuente de conflicto en esta Conferencia fue que se privilegió la participación sindical de la mujer y su militancia en las filas del Partido Comunista y que su principal consigna fue fomentar el trabajo en la retaguardia. 


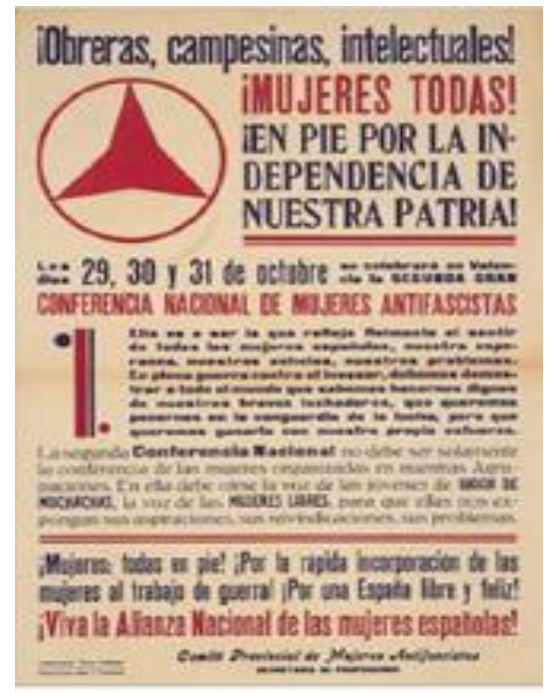

Cartel 19: Desconocido, 1938

La Segunda Conferencia Nacional de Mujeres Antifascistas se celebró en Valencia en octubre de 1938. En el cartel anunciador se expone la idea de pluralidad que debe tener la Conferencia llamando a las obreras, a las campesinas, a las intelectuales, a las jóvenes y a las mujeres de otras asociaciones para que expongan sus problemas, aspiraciones y reivindicaciones. Además con esta reunión lo que se busca es que "en plena guerra contra el invasor, debemos demostrar a todo el mundo que sabemos hacernos dignas de nuestros bravos luchadores, que queremos ponernos en la vanguardia de la lucha, pero que queremos ganarle con nuestro propio esfuerzo". Resulta llamativo el hecho de que tuvieran que demostrar si eran 'dignas', pero más llamativo es el que tuvieran que serlo para los 'bravos luchadores', ¿es que acaso el trabajo de las mujeres en la retaguardia no era lo suficientemente digno e imprescindible?

En esta Segunda Conferencia se animó a las campesinas a incorporase al trabajo industrial, se expuso la necesidad de que se elevara su nivel cultural y profesional y que se mejoraran sus condiciones sanitarias para disminuir la mortalidad infantil en las zonas rurales. Lo que no queda muy claro es que, si las campesinas se incorporaban al trabajo en las industrias, ¿quién iba a realizar el trabajo en el campo? Gran parte del trabajo de la Asociación de Mujeres Antifascistas estaba relacionado con el ejército. Se dedicaban al lavado de la ropa de los combatientes, visitaban a los heridos en los hospitales, entregaban banderas a los distintos regimientos y eran madrinas de guerra de los soldados. Todas estas actividades suponían una repetición de los roles y estereotipos a los que debían enfrentarse las mujeres en su vida diaria. 
En opinión de Carmen Grimau (1979:213) la característica más importante de los carteles comunistas es que representan a la mujer como una figura modélica y con una clara inspiración soviética "por su disciplina y abnegación a la lucha", liberada de la esclavitud de la sociedad burguesa y que ocupa un espacio privilegiado. La imagen que se muestra en el cartel 20 realizado para el Sector Oeste del Partido Comunista, pone de manifiesto que la intención de la Conferencia Internacional de Mujeres era la lucha contra el fascismo y en favor de la paz. Se presenta a una mujer de complexión fuerte vestida con el mono de trabajo, que levanta decidida un martillo, y al fondo la silueta de las chimeneas de las fábricas.

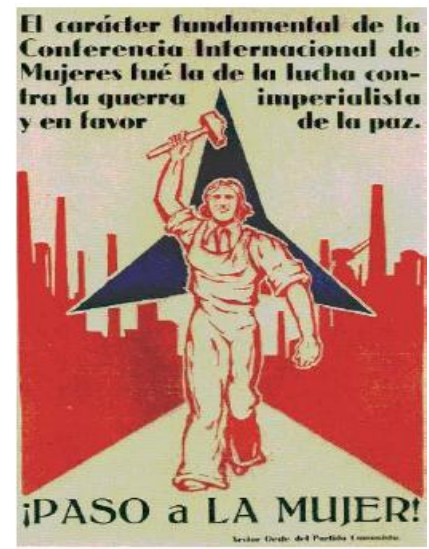

Cartel 20: Desconocido, Madrid 1937

\section{CONCLUSIONES}

Como se ha podido comprobar a lo largo del trabajo, los carteles republicanos de la Guerra Civil dirigidos a la mujer o que utilizan su imagen se pueden clasificar en dos categorías:

Por una parte, aquellos que hacen referencia a las milicianas o al trabajo de la mujer en las fábricas o en aquellos sectores en los que los hombres estaban más representados. En estos casos se utiliza una imagen 'masculinizada' de la mujer. Suele aparecer vestida con pantalón o mono de trabajo con unos rasgos muy expresivos y un cuerpo 'robusto'. Además se utilizan textos en los que se pretende provocar a los varones atacando su hombría y su virilidad.

Por otra parte, los carteles que hacen referencia a los bombardeos, a las peticiones de ayuda, incluso a la mujer en la retaguardia -enfermeras, costureras, cuidadoras y educadoras...- en estos casos la imagen se suaviza y se dramatiza ya que la mujer -supuestamente- es más débil y sumisa y lo que se busca es provocar la compasión y la solidaridad. Es muy común el que aparezca la imagen de una madre con su hijo, precisamente para conseguir llamar más la atención. 
Resulta paradójico el hecho de que se alabe la labor de las mujeres en el frente, y que, en poco tiempo cambien las tornas y las milicianas dejen de ser heroínas. ¿Por qué si en un principio estas mujeres eran valoradas y respetadas se decidió retirarlas de los frentes? ¿Por qué no las dejaron decidir por sí mismas y adoptaron una aptitud paternalista y dictatorial? La cuestión de la falta de preparación no parece muy justificada cuando se alistó forzosamente a chicos de diecisiete años cuya experiencia en la guerra no podía ser mayor que la de estas mujeres.

Se mantenía la idea de que el país no se puede detener porque los hombres impulsores del engranaje de la economía- tengan su puesto en el frente. Así que, como algo excepcional serían las mujeres las que ocuparan los puestos de trabajo dejados por los hombres. Lo que no se entiende es que si las mujeres demostraron que, aunque faltaban los brazos masculinos, el país podía seguir adelante se considerara su trabajo como algo secundario y pasajero, pues los hombres volverían a ocupar sus puestos de trabajo cuando terminara la guerra relegando de nuevo a la mujer a la casa.

Con la victoria franquista la mujer quedó relegada, de nuevo, a un segundo plano, al cuidado de la casa y de los hijos, y unas pocas 'privilegiadas' podían trabajar fuera de casa, eso sí, en actividades consideradas femeninas. Aunque una gran parte de los políticos republicanos mantuvieron una actitud igualmente fascista respecto a las mujeres, y no creían que éstas tuvieran capacidades más allá de sus tareas domésticas; además, teniendo en cuenta que el propio gobierno y los sindicatos permitieron que las mujeres que trabajaban fuera de sus casas lo hicieran en peores condiciones y con menores salarios que los varones, no se puede decir que la idea de igualdad y solidaridad que el Frente Popular utilizaba siempre en sus discursos, estuviera dirigida también a las mujeres.

La Asociación de Mujeres Antifascistas mantenía que el fascismo era el peor enemigo de las familias, de los hogares, de las mujeres, que supondría la humillación y el regreso al sistema patriarcal y autoritario, pero ¿realmente éste había desaparecido alguna vez? Por lo que se ha visto parece que no. Aunque en algunas situaciones excepcionales la mujer ocupó puestos de responsabilidad, luchó en el frente, demostró que era capaz de realizar los trabajos más duros, que tenía iniciativa política y que se interesaba por recibir formación educativa y cultural, aparte de dedicarse a su trabajo doméstico y familiar, para muchos varones seguían siendo ciudadanas 'de segunda clase'.

\section{CARTELES}

www.guerracivil.org/Carteles/ArteyPro.htm

http://www.mesames.net/uv/cas/abre.asp?pag=coleccion

www.nodo50.org

http://www.xtec.es/ aguiu1/calaix/050guerracivil.htm

http://orpheus.ucsd.edu

http://guerraespana.turincon.com/

http://www.brigadasinternacionales.org/ 


\section{BIBLIOGRAFÍA}

ALCALDE, C. (1996): Mujeres en el Franquismo: Exiliadas, nacionalistas y opositoras, Barcelona, Flor del Viento.

ALCALDE, C. y FALCÓN, L. (1976): La mujer en la Guerra Civil Española, Madrid, Cambio 16.

BLACKSMITH, M.: “Arte y propaganda política en la Guerra Civil Española”, disponible en Internet: http: www.guerracivil.org/Carteles/ArteyPro.htm [Consulta: 17 de marzo 2008).

CARULlA, J. y CARULlA, A. (1997): La Guerra Civil en 2000 Carteles, Barcelona, Postermil S.L.

FALCÓN, I. (1996): Asalto a los cielos. Mi vida junto a Pasionaria, Madrid, Temas de Hoy.

FALCÓN, L. (1992): Mujer y poder político, Madrid, Vindicación Feminista.

GRIMAU, C. (1979): El cartel republicano en la Guerra Civil, Madrid, Cátedra.

JULIÁN, I. (1993): El cartel republicano en la Guerra Civil Española, Madrid, Ministerio de Cultura.

MANGINI, S. (1997): Recuerdos de la resistencia. La voz de las mujeres de la Guerra Civil Española, Barcelona, Península.

NASH, M. (1981): Mujer y movimiento obrero en España 1931-1939, Barcelona, Fontamara.

- (1999): Rojas. Las mujeres republicanas en la Guerra Civil, Madrid, Taurus.

RENAU, J. (1976): Función Social del Cartel, Valencia, Fernando Torres Ed.

RODRIGO, A. (1996): Mujeres para la Historia. La España silenciada del siglo XX, Madrid, Compañía Literaria.

- (1999): Mujer y exilio. 1939, Madrid, Compañía Literaria.

\section{Breve currículo:}

\section{María Gómez Escarda}

Licenciada en Ciencias Políticas y Sociología por la Universidad Nacional de Educación a Distancia; Experta Universitaria en Orientación y Mediación Familiar y Experta Universitaria en Estadística para Profesionales. Becaria de investigación en el Instituto Universitario General Gutiérrez Mellado. Realizando la tesis La evolución de las políticas de bienestar familiar en las Fuerzas Armadas españolas: la adaptación organizativa a los cambios sociales y militares (19752006). Ha participado en seis proyectos de investigación y actualmente colabora en dos relacionados con la mujer en las fuerzas armadas y la opinión pública sobre política de defensa y seguridad internacional. Miembro de la Asociación Castellano-Manchega de Sociología y autora de diversas publicaciones en libros de actas, informes y revistas sobre género, familia y fuerzas armadas. 